PREPRINT

\title{
Merits and Limitations of Latent Profile Approaches to Teachers' Achievement Goals: A Multi-Study Analysis
}

\author{
Martin Daumiller \\ University of Augsburg
}

\author{
Stefan Janke \\ University of Mannheim
}

\author{
Ruth Butler \\ Hebrew University of Je- \\ rusalem
}

\author{
Oliver Dickhäuser \\ University of Mannheim
}

\author{
Markus Dresel \\ University of Augsburg
}

\begin{abstract}
Research on teacher goals has primarily followed a variable-centered approach, despite person-centered approaches having inspired achievement goal research in other domains. Following a multiple goal perspective, individuals pursue different combinations of goals - goal profiles - that might be differentially adaptive or maladaptive. We investigate how beneficial goal profiles may be for research on teacher motivation. Using data from three study sets (total $N=3,681$ ) from different countries (Israel, Germany) and institution types (schools, universities), we analyzed whether psychologically meaningful, coherent, and generalizable goal profiles can be found in different teacher populations. We investigated how such profiles are associated with self-efficacy and work-related distress, and compared their predictive power to variable-centered analyses. We found six psychologically meaningful and largely generalizable goal profiles that, compared to individual goals, explained little differences in self-efficacy and work-related distress. Given these findings, we critically evaluate achievement goal profiles as a means to study effects of teacher goals.
\end{abstract}

Keywords: goal orientation, instructor, cluster, latent profile, person-centered, variable-centered

Highlights:

- We analyzed achievement goal profiles of teachers and tested their usefulness

- We used 3 study-sets of teachers from Israel and Germany, schools and universities

- Latent profile analyses yielded six largely generalizable and meaningful profiles

- Profile membership explained differences in self-efficacy and work-related distress

- The explanatory value was very little compared to main effects of individual goals

THIS PAPER IS UNDER REVIEW.

Please do not cite or distribute any portion without authors' permission.

Research into teacher motivation has shown that teachers' achievement goal pursuit matters, for teachers themselves as well as for their teaching outcomes. Studies conducted in different countries and in different types of institutions ranging from primary schools to universities have consistently documented that different achievement goals are differentially associated with teachers' coping strategies (e.g., Parker \& Martin,

Correspondence concerning this article should be addressed to Martin Daumiller, Department of Psychology, University of Augsburg, Universitätsstr. 10, 86159 Augsburg, Germany; Martin.Daumiller@phil.uni-augsburg.de. ORCID: 0000-00030261-6143

The research reported in this article was supported by German Research Foundation Grant DI 929/5-1 to Oliver Dickhäuser and Grant DR 454/8-1 to Markus Dresel.
2009), emotional experiences (e.g., Janke et al., 2019; Wang, Hall, Goetz, \& Frenzel, 2017), well-being at work (e.g., Collie \& Martin, 2017; Fasching et al., 2010; Parker, Martin, Colmar, \& Liem, 2012), learning behaviors (e.g., Daumiller et al., 2020), and instructional practices (e.g., Butler, 2012; Butler \& Shibaz, 2008; Retelsdorf et al., 2010; Retelsdorf \& Günther, 2011). Nevertheless, the by now substantial body of empirical research on this subject has primarily relied on a variable-centered approach, which assumes population-homogeneity and considers linear associations between discrete goals and one or more theoretically relevant outcomes. Besides this approach, a multiple goal perspective has emerged within research on achievement goals (see Pintrich, 2000; Wormington \& Linnenbrink-Garcia, 2017) postulating that different subgroups of individuals can be identified that pursue 
different combinations of achievement goals, or goal profiles, that might in turn be particularly adaptive or maladaptive. This perspective has inspired a large body of person-centered research on elementary (e.g., Veermans, \& Tapola, 2004), secondary (e.g., Jang \& Liu, 2012; Tuominen-Soini, Salmela-Aro, \& Niemivirta, 2011), and higher education students (e.g., Pastor, Barron, Miller, \& Davis, 2007).

Yet when it comes to teachers, achievement goal profiles have rarely been investigated and little is known about the power of such an approach for describing their achievement motivations and explaining differences in their beliefs and behaviors. Regarding the latter, investigating differences in teachers' self-efficacy beliefs and work-related distress can be considered as particularly insightful, given that these constructs are central and well-researched aspects of teachers' professional experiences (Daumiller et al., 2020) and are often considered in profile-based investigations in students (Womrington \& Linnenbrink-Garcia, 2017). Furthermore, knowledge on teachers' achievement goal profiles is also essential for practical implications, as knowledge on different subgroups of (differentially motivated) teachers is essential for groupspecific interventions and training.

Given the lack of research in the teaching domain, the merits of person-centered approaches besides variable-based approaches for modeling achievement goal configurations within teachers are unclear. Therefore, we address the applicability of such an approach to teacher motivation by investigating the suitability of goal profiles for describing teacher motivation in a psychologically meaningful way and for predicting differences in teachers' cognitions and experiences compared to variable-centered approach.

\subsection{Achievement Goal Profiles as an Approach to Achievement Motivation}

The cornerstone of our reflections on teacher motivation constitutes the Achievement Goal Approach, which is an influential framework for explaining what motivates individuals in achievement situations. It has been applied to a broad range of populations such as students (e.g., Ames \& Archer, 1988), athletes (e.g., Duda \& Nicholls, 1992), employees (e.g., Janssen \& Van Yperen, 2004), and teachers (e.g., Butler, 2007). Within this, achievement motivation is defined in terms of qualitatively distinct types of goals characterized by the different end-states that individuals strive for in achievement situations (e.g., Elliot, 2005). In research on teacher motivation, four distinct types of achievement goals are commonly distinguished (e.g., Butler, 2007, Nitsche et al., 2011; Retelsdorf \& Günther, 2011;
Wang, Shen, Luo, Hu, \& Garn, 2017): mastery goals (i.e., striving to develop one's professional competence $)^{1}$, performance approach goals (i.e., striving to show high ability and outperform others), performance avoidance goals (i.e., striving to avoid appearing incompetent and performing worse than others), and work avoidance goals (i.e., striving to get through the day with little effort).

Several goal theorists have further differentiated teachers' achievement goals, for example by considering relational goals (i.e., striving to create positive relationships with students; Butler 2012), learning avoidance goals (i.e., striving to not do worse than before; Mascret, Elliot, \& Cury, 2017), and task goals (i.e., striving to master a task; Mascret et al., 2017; see Daumiller et al., 2019, for an overview model). In the present study, we focus on the original four goals (mastery, performance-approach, performance-avoidance, and work-avoidance) proposed by Butler (2007) as this framework has guided most of the research on teachers' achievement goals to date and thus has a strong empirical foundation. Importantly, these goals also align best with those most frequently used in person-centered studies on students' achievement goal profiles (Wormington \& Linnenbrink-Garcia, 2017), enabling us to compare the identified goal profiles to those found in prior research.

Research on goal profiles among students has largely stemmed from debates as to whether certain goals or alternatively goal combinations lead to (or at least are associated with) more effective learning (Wormington \& Linnenbrink-Garcia, 2017). The position that certain goals are superior to others is commonly labeled as the "mastery-goal perspective". Researchers adhering to this perspective state that purely pursuing mastery goals elicits the most beneficial outcome pattern (Kaplan \& Middleton, 2002; Midgley, Kaplan \& Middleton, 2001).

In contrast, advocates of the "multiple-goal perspective" share the notion that achievement goals are not mutually exclusive (see Harackiewicz, Barron, Pintrich, Elliot, \& Thrash, 2002). Besides for example specialized effects, it is argued that a certain combination of goals may lead to the most beneficial outcome pattern. This perspective has primarily emerged from the mixed pattern of results for performance approach goals (Wormington \& Linnenbrink-Garcia, 2017), which correlate with outcomes deemed desirable such as high achievement, as well as with undesirable outcomes such as increased test anxiety (see also Janke et al., 2016, for an overview). Advocates of this perspective often claim that performance approach goals are 
especially beneficial when adopted alongside mastery goals, such that the strong endorsement of both goals is equally or more beneficial than the endorsement of strong mastery goals alone (Pintrich, 2000; Senko, Hulleman, \& Harackiewicz, 2011). While this assumption can be tested with interaction terms within the General Linear Model, the multiple goal approach also sparked a more general debate as to whether variablecentered approaches are appropriate in the first place, given the number and complexity of possible goal patterns (Wormington \& Linnenbrink-Garcia, 2017). These considerations led to a growing popularity of person-centered investigations into students' goal profiles.

\subsection{Merits and Limitations of Person-Centered Analyses into Achievement Goals}

While variable-centered analyses allow for investigations into associations between variables within certain populations, person-centered analyses such as Cluster Analyses or Latent Profile Analyses (LPAs) enable researchers to identify subgroups of individuals that differ from one another regarding the investigated variables (Wormington \& Linnenbrink-Garcia, 2017). In line with prior research on achievement goal profiles, we use the term person-centered to refer to research that identifies and compares subgroups of individuals based on mean differences where individuals with similar expressions in a bundle of variables are grouped together. Person-centered analyses into achievement goals allow for insight into potential goal configurations (i.e., goal profiles) that differentiate groups of individuals based on how the various goals combine within individuals, while also maintaining the power of subsequent analyses into correlates of these goal profiles. This can be illustrated by comparing variable- versus person-centered approaches for the four goals that are typically used to characterize teachers' achievement goals. Using a variable-centered approach, it would be necessary to consider four main effects, six two-way interactions, four three-way interactions, and one four-way interaction to investigate the impact of every possible goal composition (e.g., see Elliot \& McGregor, 2001). Analyses into so many complex interactions on top of main effects likely face problems regarding statistical power (Shieh, 2009) and interpretability (Morin, 2016). Furthermore, variablecentered approaches rely on the assumption of population-homogeneity and linear interactions among all goal levels. In contrast, person-centered approaches relax the assumption of population-homogeneity and allow for the identification of goal profiles that are potentially suitable to characterize groups within a certain population, usually resulting in a much smaller number of profiles (compared to the amount of possible interactions). Further, Wormington and Linnenbrink-Garcia (2017) noted in their meta-analysis on goal profiles that, compared to variable-centered approaches, person-centered approaches may be more useful to model the effects of performance approach and performance avoidance goals (which are often very strongly associated, see Janke et al., 2016). Finally, person-centered approaches afford comparisons between individuals characterized by a certain goal profile and individuals characterized by another goal profile, allowing for a better understanding of how goal compositions relate to adaptive patterns of experiences and behaviors. This advantage is particularly relevant for examining the contrasting predictions of the "mastery goal" and "multiple goals" perspectives as the latter assumes that the combination of strong mastery and performance goals will be beneficial mainly to the extent that they combine also with weak performance-avoidance goals.

Despite these potential benefits, an important premise of using person-centered analyses to investigate achievement goal striving is that similar motivational profiles can be found across different contexts. If this is not the case, findings from different samples cannot be sufficiently compared (see Litalien, Morin, \& McInerney, 2017; Wormington \& Linnenbrink-Garcia, 2017). Further, person-centered analyses into achievement goal striving can only provide substantial insights into differences in beliefs and behaviors if goal profiles do indeed explain meaningful amounts of variance compared to the main effects of the single goals, as suggested by advocates of the multiple goal perspective (see also Marsh et al., 2007). This notion, however, is rarely reflected in the methodology of studies examining goal profiles (Jang \& Liu, 2012; Pastor, et al., 2007; Tuominen-Soini, et al., 2011), as the necessary investigations would require combining and comparing person-centered and variable-centered analyses (see Linnenbrink-Garcia et al., 2012, for a comparison of person and variable centered approaches to explain differences in students' changes in conceptual understanding). Besides the extent to which profiles are generalizable and theoretically reasonable, a strong case for the usefulness of the multiple goal perspective in explaining differences in educational outcomes requires that the profiles explain substantial portions of variance compared to the main effects of the individual goals.

In their meta-analytical review including a large set of studies of students' goal profiles, Wormington and Linnenbrink-Garcia (2017) found that almost half of around 15,000 students (49.1\%) were not characterized 
by qualitatively different configurations of stronger and weaker goals. Rather, there were quantitative differences in the general levels of achievement motivation such that the levels of all goals were average, high, or low. Wormington and Linnenbrink-Garcia (2017) interpreted this finding to indicate that the levels of achievement goal striving may be as important as the relative strength of goals for describing students' goal pursuit. Using other motivational frameworks such as Self-determination Theory, person-centered approaches often document similar findings about the prevalence of qualitative and quantitative differences in motivational profiles (e.g., Vansteenkiste, Sierens, Soenens, Luyckx, \& Lens, 2009). Taking a critical stance, one might interpret a large proportion of profiles only differing by quantitative differences as challenging a person-centered approach, as it highlights the necessity to compare mean values, which can be achieved more directly with variable-centered approaches. Moreover, as the quantitative differences in motivational profiles align primarily with older approaches that often defined achievement motivation as a one-dimensional, quantitative motivational force, one might even argue that such findings do not align well with the fundamental assumptions of Achievement Goal Theory and Self-determination Theory on the quality of motivation mattering.

In sum, a person-centered approach could advance research into teachers' achievement goals - if it helps to differentiate teachers alongside goal profiles that are meaningful (i.e., characterized by qualitative and theoretically reasonable differences rather than quantitative differences in achievement motivation), generalizable (e.g., found in different groups of teachers), and explain substantial variance in other variables (compared to the main effects of the individual achievement goals).

\subsection{Potential Goal Profiles Within Teacher Popula- tions}

Beyond the finding that about half of the students in the reviewed studies could be characterized by the general strength of their achievement goals, Wormington and Linnenbrink-Garcia (2017) found two profiles to frequently (but not always) emerge that were characterized to a stronger degree by qualitative rather than only quantitative differences regarding goal pursuit. In particular, these goal profiles allow for deeper comparison of the mastery goal perspective versus the multiple goal perspective. The first qualitatively differentiated goal profile identified in $62.5 \%$ of all investigated samples was indicated by elevated mastery goals. According to the mastery-goal perspective, individuals that are char- acterized by this goal profile should show the most beneficial learning behavior when compared to any other goal profile. The second goal profile identified in 50\% of all investigated samples was indicated by strong mastery and strong performance approach goals. This goal profile is of particular interest for scholars expecting interactive goal patterns following the multiplegoal perspective, as comparisons between individuals with this goal profile to other groups (especially with individuals characterized by exclusively strong mastery goals) could indicate whether the combination of strong performance approach goals and strong mastery goals is particularly beneficial. Replicating these two goal profiles within teacher populations would be of great interest in order to test the applicability of the mastery- versus multiple-goal perspectives within the population of teachers.

To the best of our knowledge, the only published study on goal profiles in the teaching profession was reported by Kunst, van Woerkom, and Poell (2018), who analyzed work goal orientations of 984 vocational training instructors from the Netherlands. The authors found that $50.1 \%$ were classified into a "diffuse" profile with average levels of all goals, $10.7 \%$ into a high mastery and performance approach goal profile, and $12.3 \%$ into a low performance approach and performance avoidance goal profile. These three profiles are conceptually similar to the three previously described profiles reported by Wormington and LinnenbrinkGarcia (2017). In line with the multiple goal perspective, Kunst et al. (2018) found that teachers who were classified into the high mastery and performance approach goal profiles reported more information acquisition and feedback asking than those in the other profiles. However, it is also worth noting that Kunst et al. (2018) did not identify a high mastery profile, but only a profile with moderate mastery goals and weak performance goals. Nevertheless, this affirms the notion of investigating goal profiles also in teachers and expecting, in principle, similar patterns as in students (see Van den Berghe et al., 2014, for qualitative differences in motivational profiles in teachers using a SDT framework).

\subsection{Relevant Correlates for Research into Teachers' Goal Profiles}

Beyond the existence of achievement goal profiles in students, Wormington and Linnenbrink-Garcia (2017) investigated whether students who were characterized by certain goal profiles also differed in other motivational variables and their social and emotional well-being. In the reviewed articles, they found the strongest support for the view that a high-mastery goal 
profile was most beneficial with regard to these outcomes when compared to any other goal profile. While this provides some support for the mastery-goals perspective within students, a conceptual replication in samples of teachers would support the generalizability of findings and the usefulness of person-centered approaches on achievement-motivation. With that being said, studies on teachers' achievement goals that have applied the variable-centered approach frequently showed positive associations between mastery goals and other aspects of teachers' motivation such as selfefficacy beliefs (Cho \& Shim, 2013; Gorozidis \& Papaioannou, 2011) and teachers' well-being (Parker et al., 2012; Retelsdorf et al., 2010).

In order to relate our research to the broader picture of research into teachers' goals, we chose to investigate two variables that are central to teachers' cognitions and experiences at work and that have often been investigated in prior (variable-centered) studies of teachers' achievement goals: teachers' self-efficacy (reflecting an expectancy-based aspect of motivation aside from the goals that are grounded in the value-component of motivation) and work-related distress (as proxy for impaired well-being).

Teachers' self-efficacy beliefs describe teachers' self-ascribed capabilities to influence student learning (Klassen \& Chiu, 2010). Teachers' self-efficacy is positively related to both mastery and performance approach goals, while being negatively associated with performance avoidance goals and especially with work avoidance goals (e.g., Cho \& Shim, 2013; Daumiller et al., 2016; Janke et al., 2019; Nitsche, 2011). As far as we are aware, no empirical studies to date have investigated whether there is any effect of the goal composition beyond the additive influence of both goals. Fundamentally, we want to investigate whether teachers who are characterized by strong mastery and performance approach goals (multiple goals) experience substantially higher self-efficacy than those who merely report strong mastery goals or strong performance approach goals.

Experiences of work-related distress in teachers have often been operationalized as burnout experiences defined by feelings of exhaustion at work, reduced personal accomplishment, and depersonalization (Hakanen, Bakker, \& Schaufeli, 2006). Research has confirmed strong links between achievement goals and burnout levels (Parker et al., 2012; Retelsdorf et al., 2010) but also with other measures of work-related distress such as occupational strain (Nitsche et al., 2013). Mastery goals were negatively associated with experi- ences of work-related distress, and performance avoidance goals and work avoidance goals (the latter to an even greater extent) were positively related to such experiences. The pattern of results was more inconclusive for performance approach goals, which showed either positive associations (Nitsche et al., 2013) or, more typically, null effects (e.g., Retelsdorf et al., 2010). This leaves room for speculation on whether feelings of distress can differently emerge from a combination of different (performance) goals. For example, performance approach goals might be associated with distress if combined with strong performance avoidance or work avoidance goals, while no such association, or possibly even a negative association, may be found if instead accompanied by strong mastery goals. A person-centered approach could shed light on these complex relations.

\section{Research Questions}

Our overarching objective was to investigate achievement goal profiles of teachers and their meaningfulness compared to the insights provided by variable-centered approaches. Our first research question was whether it is possible to consistently identify achievement goal profiles, which indicate qualitative rather than quantitative differences in achievement goal strivings, between subgroups of teachers (particularly in terms of strong mastery goals but not strong performance goals, and strong mastery goals combined with strong performance goals). One serious problem of the person-centered approach is that the emergence of some goal profiles might strongly depend on the respective sample. For instance, Wormington and Linnenbrink-Garcia (2017) pointed out that half of the goal profiles identified in their meta-analysis only emerged in less than 25 percent of the investigated student samples. This means that we have to be cautious in overinterpreting results from single samples of teachers. To overcome this problem, we included a set of samples from different countries (Israel, Germany) and different teaching contexts (i.e. primary/secondary versus higher education) to investigate the robustness of the observed goal profiles. Specifically, we examined whether the profile patterns varied in dependence on systematic differences between the addressed teacher populations (country, institution type) or whether we would be able to find generalizable profiles across different populations.

As a second research question, we investigated whether teachers with different goal profiles also differed in their self-efficacy beliefs and experiences of work-related distress. Building on this, our third research question was whether the person-centered latent profile approach can deliver insights into associations 
Table 1

Overview of the Included Datasets

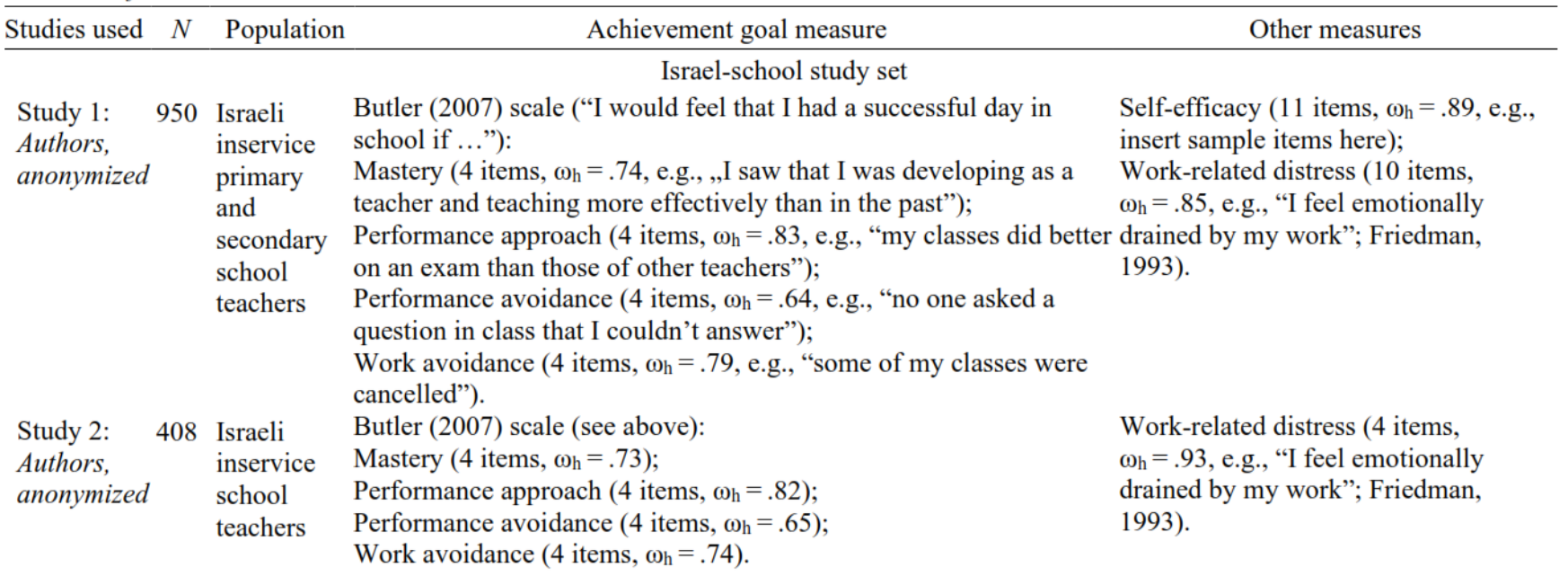

\section{German-university study set}

Study 3: 933 German Daumiller et al. (2019) scale ("In my current teaching activities ...": Self-efficacy ${ }^{\mathrm{b}}\left(12\right.$ items, $\omega_{\mathrm{h}}=.86$, e.g., Authors, university Mastery (4 items, $\omega_{\mathrm{h}}=.88$, e.g., "my goal is to expand my "How well can you respond to anonymized teachers professional and methodological knowledge as much as possible"); difficult questions from your Performance approach ${ }^{\mathrm{a}}\left(8\right.$ items, $\omega_{\mathrm{h}}=.92$, e.g., "my goal is to teach students?"; adaption from Nie, Lau \& better than my colleagues"); Performance avoidance ${ }^{\mathrm{a}}\left(8\right.$ items, $\omega_{\mathrm{h}}=.93$, e.g., "my goal is to not Work-related distress $\mathrm{c}^{\mathrm{c}}(17$ items, teach worse than my colleagues do");

Work avoidance ( 4 items, $\omega_{\mathrm{h}}=.94$, e.g., "it is my goal to have the least amount of work as possible").

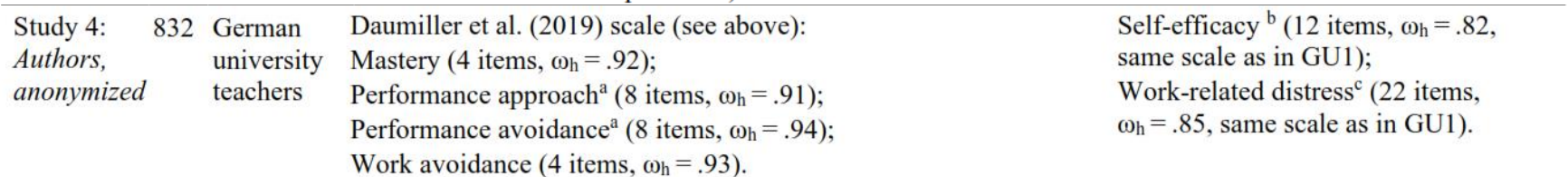
Work avoidance ( 4 items, $\left.\omega_{\mathrm{h}}=.93\right)$.

\section{German-school study set}

Study 5: 224 German $\quad$ Nitsche et al. (2011) scale ("In my vocation, I aspire to ...) : Authors, inservice Mastery (18 items, $\omega_{\mathrm{h}}=.92$, e.g., "improve my pedagogical anonymized secondary knowledge and competence."); school Performance approach $\left(6\right.$ items, $\omega_{\mathrm{h}}=.90$, e.g.,"show my colleagues teachers that I deal better with critical lessons than other teachers"); Performance avoidance (6 items, $\omega_{\mathrm{h}}=.91$, e.g., "conceal from my colleagues when I do something less satisfying than other teachers"); Work avoidance (6 items, $\omega_{\mathrm{h}}=.85$, e.g.," get through the day with little effort.").

Study 6: 334 German Nitsche et al. (2011) scale (see above):

Authors, inservice Mastery $\left(9\right.$ items, $\left.\omega_{\mathrm{h}}=.88\right)$;

anonymized secondary Performance approach $\left(3\right.$ items, $\left.\omega_{\mathrm{h}}=.84\right)$;

school Performance avoidance $\left(3\right.$ items, $\left.\omega_{\mathrm{h}}=.84\right)$;

teachers Work avoidance $\left(3\right.$ items, $\left.\omega_{\mathrm{h}}=.80\right)$.

Self-efficacy $\left(7\right.$ items, $\omega_{\mathrm{h}}=.73$, e.g., "When I try really hard, I am able to reach even the most difficult students"; Schwarzer \& Hallum, 2008);

Work-related distress (15 items, ; $\omega_{\mathrm{h}}=.88$, e.g.,"'The pressure under which I am working is too big"; Enzmann \& Kleiber, 1989).

Self-efficacy ${ }^{\mathrm{d}}\left(5\right.$ items, $\omega_{\mathrm{h}}=.74$, "Considering the challenges that my occupation poses to me, I get along well in my job"; Schöne et al., 2012); Work-related distress ${ }^{\mathrm{e}}(6$ items, $\omega_{\mathrm{h}}=.84$, same scale as in GS1).

Note. ${ }^{\text {a }}$ This scale distinguishes between appearance and normative aspects of performance and assesses them separately; for the investigation at hand, we combined both aspects to correspond to the measures of the other studies.

${ }^{\mathrm{b}}$ This scale distinguishes self-efficacy for instruction, classroom management, and motivation; again, we combined all three aspects as a general measure of teaching self-efficacy.

${ }^{\mathrm{c}}$ This scale distinguishes emotional exhaustion, depersonalization in the workplace, and reduced personal accomplishment; we again combined all three aspects.

${ }^{\mathrm{d}}$ In this dataset, self-efficacy in a narrow sense was not measured, but rather core-efficacy beliefs in the form of self-concept. We conducted the analyses twice, once with and once without this measure to ensure that our findings were not affected by the use of this measure that is slightly different to the other self-efficacy scales, albeit strongly related to self-efficacy beliefs. 
of teachers' achievement goal striving with self-efficacy beliefs and experiences of work-related distress that cannot easily be obtained using a variable-centered approach. Specifically, we investigated the explanatory power of goal profiles and set this in relation to the additive main effects of the individual achievement goals.

\subsection{Procedure and Sample}

\section{Method}

To examine the research questions, we used existing datasets from two different countries and two different educational contexts. In total, we used six datasets from studies that were conceptually similar regarding their focus on teachers, their cross-sectional design, and the measures used. Two studies were conducted with primary and secondary school teachers in Israel $(n=950$ and $n=408$ ), two studies with university teachers in Germany ( $n=933$ and $n=832)$, and two studies with secondary school teachers in Germany $(n=224$ and $n=334$ ). Table 1 provides an overview of all included datasets, reference publications, and details about their sample. As the two data sets from each of the three different educational contexts are very similar, we combined them to yield large datasets capable of identifying relevant profiles. This eventuated in three study sets (Israel-school, German-university, German-school) that were used to conduct the LPAs.

\subsection{Measures}

An overview of the measures in the different studies including sample items and internal consistencies (McDonalds Omega), which were all satisfactory, can be found in Table 1 .

Achievement goals. Regarding teachers' achievement goals, mastery approach goals (measured by learning approach goals as a core aspect of the superordinate mastery goal construct), performance approach goals, performance avoidance goals, and work avoidance goals were measured using three established scales for the three study sets, namely scales by Butler (2007), Daumiller et al. (2019), and Nitsche (2011). These scales are conceptually similar, however differ slightly in their measures. Most notably, Daumiller et al. (2019) distinguished performance goals further, as to whether they focus on appearance aspects or normative aspects. As the other two scales include items that address both of these aspects, we aggregated both appearance and normative goals for the studies that used the Daumiller et al. (2019) measure to enhance comparability with the other two scales. In addition, the Nitsche et al. (2011) scale distinguishes three facets of the content of mastery goals as well as four facets of different addresses of performance goals. These were also aggregated on the overall goal level (see Janke et al., 2019 for a similar approach).

Self-efficacy beliefs. To assess teachers' self-efficacy, the Israel-school studies used a Hebrew translation of Tschannen-Moran \& Hoy's (2001) short measure of teacher self-efficacy, the German-university studies an adaption of the scale by Lau, Nie, and Liau (2012), and the German-school studies a German version of the teacher self-efficacy scale by Schwarzer and Hallum (2008). To enhance comparability of all scales across the different study sets, we aggregated the subscales that distinguished between different aspects of self-efficacy beliefs on overall scale level.

Work-related distress. Regarding teachers' workrelated distress, the Israel-school studies used measures based on the Maslach Burnout Inventory for teachers (MBI, Büssing \& Glaser, 1998; Maslach \& Jackson, 1986) that were developed and validated for teachers in Israel by Friedman and Farber (1991). The Germanuniversity studies also used a scale based on the MBI, and the German-school studies used the perceived overload subscale by Enzmann and Kleiber (1989). We aggregated the MBI measures that distinguished different components of work-related distress (emotional exhaustion, cynicism, reduced personal accomplishment) as a composite measure to ensure comparability of all scales between study sets.

\subsection{Missing Values}

Overall, there was relatively little missing data $(<$ $2.1 \%$ for each variable, for each dataset) that was handled using the full-information maximum likelihood estimation (FIML) and the EM-algorithm for all analyses (Peugh \& Enders, 2004).

\subsection{Analyses}

As the individual studies used different scales that did not always have the same number of answer options (see Table 1), we first $z$-standardized all variables (except for gender) for each individual dataset. For the LPAs, we followed the procedure outlined by Asparouhov and Muthén (2013) using Mplus 8.1 (Muthén \& Muthén, 2017). Based on the teachers' answers to their mastery, performance approach, performance avoidance, and work avoidance goals, we first specified two latent profiles. We subsequently increased the number of profiles until the increase in model fit no longer indicated specifying another profile and losing model parsimony. Based on the range of profile found in prior research, we considered up to 9 latent profiles. Models were estimated using 5,000 random sets of start values, 100 iterations for each random start, and 200 best solutions retained for final stage optimization (Hipp \& Bauer, 2006). All solutions converged on 
Table 2

Descriptive Statistics for all Included Datasets (Displayed are Percentages for the Proportion of Female and Means and Standard Deviations for the Remaining Characteristics)

\begin{tabular}{|c|c|c|c|c|c|c|c|c|}
\hline & $\begin{array}{c}\% \\
\text { Female }\end{array}$ & $\begin{array}{l}\text { Years of } \\
\text { teaching } \\
\text { experience }\end{array}$ & $\begin{array}{l}\text { Mastery } \\
\text { (learning } \\
\text { approach) } \\
\text { goals }\end{array}$ & $\begin{array}{l}\text { Performance } \\
\text { approach } \\
\text { goals }\end{array}$ & $\begin{array}{c}\text { Performance } \\
\text { avoidance } \\
\text { goals }\end{array}$ & $\begin{array}{l}\text { Work } \\
\text { avoidance } \\
\text { goals }\end{array}$ & $\begin{array}{c}\text { Self- } \\
\text { efficacy }\end{array}$ & $\begin{array}{l}\text { Work- } \\
\text { related } \\
\text { distress }\end{array}$ \\
\hline \multicolumn{9}{|l|}{ Israel school teachers } \\
\hline Study 1: Authors, anonymized & 91 & $15.90(9.51)$ & $4.13(0.62)$ & $3.43(0.91)$ & $2.94(0.77)$ & $2.56(0.88)$ & $3.89(0.56)$ & $2.63(0.63)$ \\
\hline Study 2: Authors, anonymized & 88 & $14.04(9.63)$ & $4.17(0.61)$ & $2.07(1.97)$ & $2.73(0.88)$ & $2.18(0.93)$ & - & $2.65(0.87)$ \\
\hline \multicolumn{9}{|l|}{ German university teachers } \\
\hline Study 3: Authors, anonymized & 49 & - & $4.23(0.71)$ & $3.36(0.93)$ & $3.69(0.99)$ & $1.70(1.02)$ & $3.67(0.57)$ & $1.82(0.73)$ \\
\hline Study 4: Authors, anonymized & 36 & $11.54(9.13)$ & $4.29(0.76)$ & $2.89(0.99)$ & $3.44(1.15)$ & $1.58(1.01)$ & $3.70(0.51)$ & $2.14(0.50)$ \\
\hline \multicolumn{9}{|l|}{ German school teachers } \\
\hline Study 5: Authors, anonymized & 67 & $13.7(11.8)$ & $4.17(0.51)$ & $2.42(0.91)$ & $2.39(0.95)$ & $2.33(0.87)$ & $3.78(0.52)$ & $2.21(0.61)$ \\
\hline Study 6: Authors, anonymized & 72 & $11.13(11.6)$ & $4.34(0.48)$ & $1.99(0.90)$ & $2.28(0.98)$ & $2.34(0.96)$ & $4.08(0.50)$ & $2.85(0.78)$ \\
\hline
\end{tabular}

Note. $N=3,681$ teachers. For comparability of the descriptive statistics, goals, self-efficacy, and work-related distress have been rescaled to 1-5. "-" indicates that this variable was not assessed in the respective study.

well-replicated loglikelihood values. Changes in model fit were investigated with the Bayesian information criterion (BIC) and the sample-size-adjusted BIC (SSBIC). ${ }^{2}$ We analyzed the progressions of these model fit indices to compare models with different numbers of profiles that were interpreted by visual inspection comparable to scree plots (Cattell, 1966) by selecting the profile after which the decrease in model fit was substantially lower compared to the previous profiles (Morin et al., 2011). In addition, we used the Vuong-Lo-Mendell-Rubin likelihood ratio test (VLMR) as well as the Lo-Mendell-Rubin adjusted likelihood ratio test (LMR) to compare models with adjacent numbers of profiles. A significant $p$-value of these two tests indicates that a particular profile solution fits the data better than a model with one profile less. Finally, we also considered model parsimony (preferring simpler solutions over more complex ones), the statistical adequacy of the solution (e.g., absence of negative variance estimates; Bauer \& Curran, 2004), and ease of interpretation (preferring solutions that yield profiles that differ in quality and not solely mean levels and that can be sensibly interpreted). Subsequently, we obtained the most likely profile membership for each teacher (i.e., the profile to which an individual most likely belongs) based on the posterior distributions. The respective classification error of this procedure is reflected in the entropy values, with high values indicating small error.

We conducted this procedure for each for the three study sets (Israel-school, Germany-university, Germany-school) and once for an overall dataset contain- ing all data from the individual studies. We then compared the number of profiles found and their configuration between study sets with the solution found in the overall dataset. To investigate the generalizability of the profiles and possible context effects, we examined whether the likelihood of profile membership depended on the study sets by conducting a multivariate regression. Significant associations between the likelihood of profile membership and the study sets indicated that profile membership is at least partly a function of the different studies.

Finally, we used the profile membership obtained from the analyses of the overall dataset to examine the association of goal profiles with self-efficacy and work-related distress. To this end, we conducted equality tests of means across profiles using the $\mathrm{BCH}$ procedure (Asparouhov \& Muthén, 2014). Subsequently we compared the exploratory power of goal profiles with the individual goals by estimating structural equation models. Model 1 investigated goal profiles as predictors and Model 2 investigated the individual achievement goals. In each model, self-efficacy and work-related distress were regressed on these predictors. Achievement goals, self-efficacy, and work-related distress were estimated as latent variables based on item parcels as indicators (using the item-to-construct method, two parcels were used for each construct; see Little, Cunningham, \& Shahar, 2002).

\section{Results}

Descriptive statistics for all analyzed datasets are presented in Table 2 . 
Table 3

Overview of LPA Profile Solutions

\begin{tabular}{|c|c|c|c|c|c|c|c|c|c|c|c|c|c|c|c|}
\hline \multirow{2}{*}{$\begin{array}{c}\text { Number } \\
\text { of } \\
\text { profiles }\end{array}$} & \multicolumn{3}{|c|}{ Fit indices } & \multicolumn{2}{|c|}{$\begin{array}{l}\text { Likelihood ratio } \\
\text { tests ( } p \text { values) }\end{array}$} & \multirow[b]{2}{*}{ Entropy } & \multicolumn{9}{|c|}{ Number of teachers in profiles } \\
\hline & BIC & SSBIC & AIC & $\begin{array}{l}\text { VLMR } \\
\end{array}$ & LMR & & 1 & 2 & 3 & 4 & 5 & 6 & 8 & 9 & \\
\hline \multicolumn{15}{|c|}{ Israel-school study set } & \\
\hline 2 & 14,831 & 14,790 & 14,763 & $<.001$ & $<.001$ & .66 & 7895 & 569 & & & & & & & \\
\hline 3 & 14,721 & 14,664 & 14,627 & $<.001$ & $<.001$ & .63 & 7543 & 3122 & 292 & & & & & & \\
\hline 4 & 14,705 & 14,632 & 14,585 & .08 & .08 & .55 & 4093 & 3793 & 3022 & 268 & & & & & \\
\hline 5 & 14,684 & 14,595 & 14,538 & .56 & .56 & .62 & $467 \quad 2$ & $294 \quad 2$ & $290 \quad 2$ & 2852 & 22 & & & & \\
\hline 6 & 14,692 & 14,587 & 14,519 & .03 & .04 & .64 & $476 \quad 3$ & $304 \quad 2$ & $256 \quad 1$ & $188 \quad 1$ & 1003 & 34 & & & \\
\hline 7 & 14,699 & 14,578 & 14,501 & .19 & .19 & .65 & $374 \quad 3$ & $353 \quad 2$ & $254 \quad 2$ & 208 & 92 & 74 & 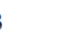 & & \\
\hline 8 & 14,713 & 14,576 & 14,489 & .21 & .21 & .67 & 362 & $355 \quad 2$ & $234 \quad 1$ & $185 \quad 1$ & 1175 & 53 & 3 & & \\
\hline 9 & 14,726 & 14,574 & 14,476 & .61 & .61 & .70 & $359 \quad 3$ & $354 \quad 1$ & $\begin{array}{ll}181 \quad 1\end{array}$ & 170 & 79 & 74 & 67 & 3 & \\
\hline \multicolumn{16}{|c|}{ German-university study set } \\
\hline 2 & 17,880 & 17,839 & 17,809 & $<.001$ & $<.001$ & .79 & 1,2545 & 511 & & & & & & & \\
\hline 3 & 17,486 & 17,429 & 17,387 & .001 & .002 & .83 & $1,217 \quad 3$ & $\begin{array}{ll}370 \quad 1\end{array}$ & 178 & & & & & & \\
\hline 4 & 17,200 & 17,127 & 17,074 & .002 & .002 & .80 & 1,0193 & $356 \quad 2$ & $245 \quad 1$ & 145 & & & & & \\
\hline 5 & 17,020 & 16,931 & 16,867 & .003 & .003 & .74 & 6515 & $556 \quad 2$ & $236 \quad 2$ & $203 \quad 1$ & 119 & & & & \\
\hline 6 & 16,899 & 16,795 & 16,719 & .04 & .04 & .76 & $657 \quad 5$ & $524 \quad 2$ & $200 \quad 1$ & $189 \quad 1$ & 158 & 37 & & & \\
\hline 7 & 16,871 & 16,750 & 16,663 & .35 & .36 & .77 & 6465 & $515 \quad 1$ & $191 \quad 1$ & $177 \quad 1$ & 172 & 52 & 2 & & \\
\hline 8 & 16,820 & 16,683 & 16,584 & .59 & .59 & .78 & $647 \quad 4$ & $484 \quad 1$ & $195 \quad 1$ & $179 \quad 1$ & 106 & 86 & 15 & & \\
\hline 9 & 16,782 & 16,629 & 16,519 & .18 & .19 & .78 & 6613 & $396 \quad 1$ & $186 \quad 1$ & $168 \quad 1$ & 152 & 73 & 45 & 12 & \\
\hline \multicolumn{15}{|c|}{ German-school study set } & \\
\hline 2 & 6,095 & 6,053 & 6,038 & $<.001$ & $<.001$ & .73 & 286 & 271 & & & & & & & \\
\hline 3 & 6,058 & 6,001 & 5,980 & .11 & .12 & .74 & 289 & 207 & 61 & & & & & & \\
\hline 4 & 6,027 & 5,954 & 5,928 & .56 & .57 & .80 & 288 & 209 & 57 & 3 & & & & & \\
\hline 5 & 6,026 & 5,937 & 5,905 & .07 & .07 & .80 & 195 & 190 & 144 & 27 & 2 & & & & \\
\hline 6 & 6,030 & 5,925 & 5,887 & .52 & .53 & .81 & 195 & 189 & 35 & 28 & 8 & 3 & & & \\
\hline 7 & 6,034 & 5,914 & 5,870 & .35 & .36 & .81 & 189 & 175 & 128 & 38 & 19 & 6 & 3 & & \\
\hline 8 & 6,041 & 5,904 & 5,855 & .54 & .54 & .79 & 180 & 154 & 125 & 50 & 27 & 14 & 6 & 2 & \\
\hline 9 & 6,052 & 5,900 & 5,844 & .01 & .01 & .82 & 185 & 154 & 118 & 50 & 27 & 16 & 6 & 1 & 1 \\
\hline \multicolumn{16}{|c|}{ Overall dataset } \\
\hline 2 & 38,902 & 38,861 & 38,821 & $<.001$ & $<.001$ & .71 & 2,376 & 61,305 & & & & & & & \\
\hline 3 & 38,527 & 38,470 & 38,415 & $<.001$ & $<.001$ & .77 & 2,372 & 21,058 & 8251 & & & & & & \\
\hline 4 & 38,222 & 38,149 & 38,079 & $<.001$ & $<.001$ & .70 & 1,611 & 11,340 & 0580 & 150 & & & & & \\
\hline 5 & 38,086 & 37,997 & 37,912 & .004 & .004 & .66 & 1,557 & 71,017 & 7555 & 408 & 144 & & & & \\
\hline 6 & 37,937 & 37,832 & 37,732 & .005 & .004 & .69 & 1,441 & 1926 & 552 & 485 & 211 & 166 & & & \\
\hline 7 & 37,880 & 37,759 & 37,644 & .40 & .41 & .71 & 1,451 & 1883 & 546 & 502 & 197 & 79 & 23 & & \\
\hline 8 & 37,825 & 37,689 & 37,558 & .21 & .21 & .70 & 1,323 & 3940 & 491 & 366 & 210 & $0 \quad 180$ & 141 & 30 & \\
\hline 9 & 37,777 & 37,624 & 37,479 & .32 & .32 & .70 & 1,224 & 4850 & 491 & 348 & 304 & $4 \quad 250$ & 153 & 37 & 24 \\
\hline
\end{tabular}

Note. BIC $=$ Bayesian information criterion. SSA-BIC $=$ sample-size-adjusted BIC. AIC $=$ Akaike information criterion. VLMR $=$ Vuong-Lo-Mendell-Rubin likelihood ratio test. $\mathrm{LMR}=$ Lo-Mendell-Rubin adjusted likelihood ratio test.

\subsection{Number of Profiles}

The results of the LPAs for the three study sets as well as the overall dataset are presented in Table 3 . We estimated and compared models comprising between two and nine profiles.

For the Israel-school study set, the differences in AIC, BIC, and SSBIC fit values were small after a three-profile solution and negligible after a six-profile model. For subsequent (i.e., seven and more profile so- lutions) models, we did not observe a good class discrimination as the new profiles were of low frequency and primarily indicated differences in the quantity but not in the quality of achievement goal striving. The three-profile solution was characterized by three profiles that indicated whether mastery goals were endorsed alongside weak, moderate, or strong performance approach, performance avoidance, and work avoidance goals. The six-profile solution, however, indicated qualitatively more complex goal profiles that 


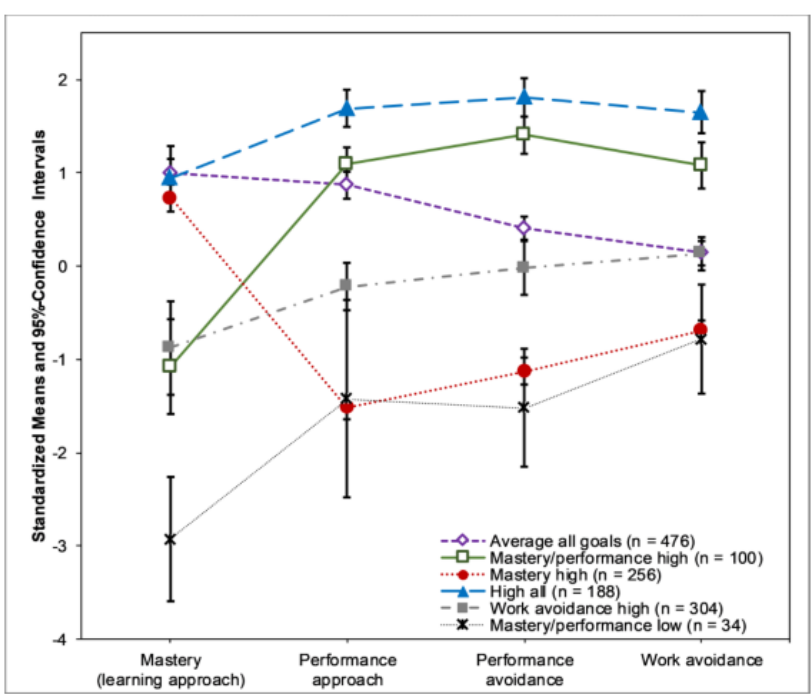

(a) Israel school teachers

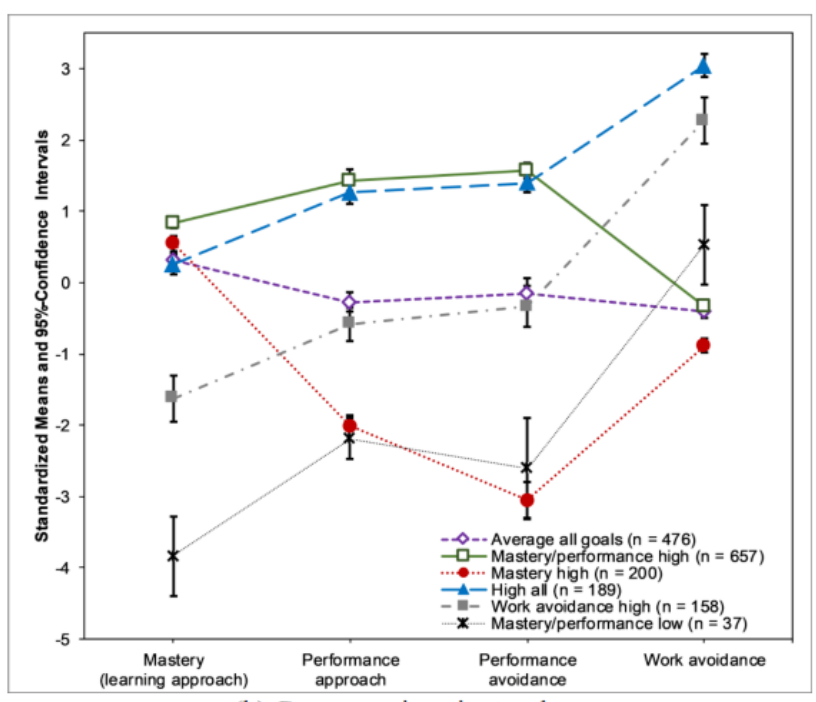

(b) German university teachers

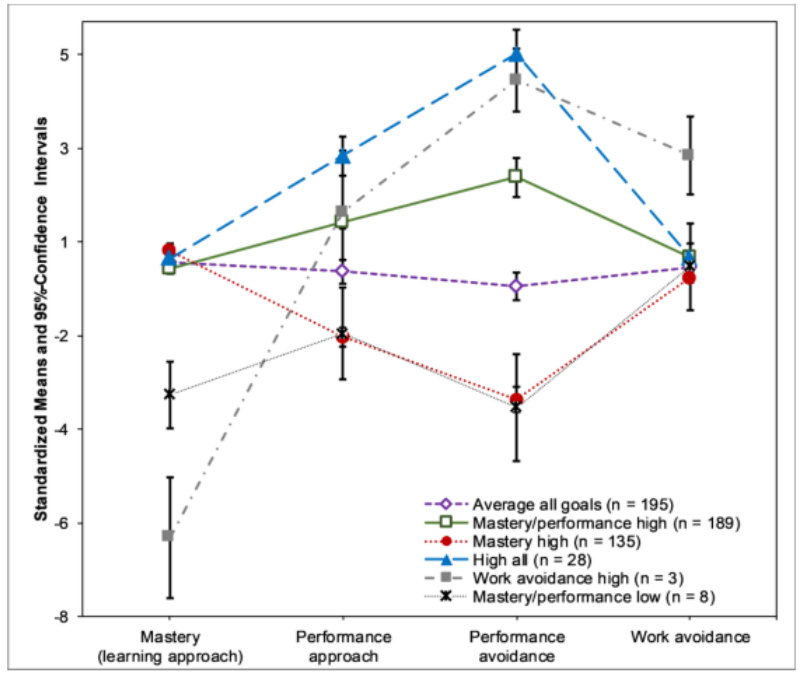

(c) German school teachers

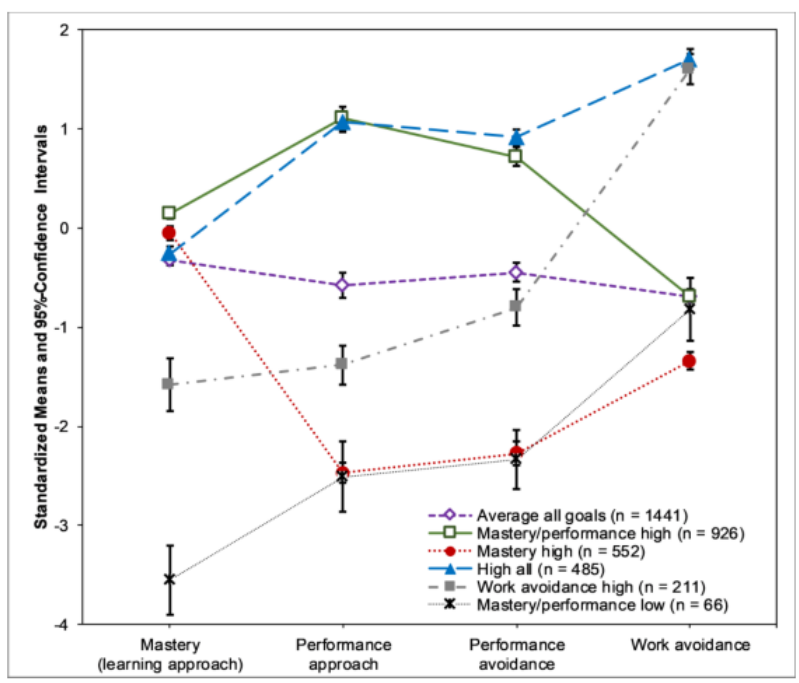

(d) Overall

Figure 1. Goal means for the six latent profiles (with $95 \%$ confidence intervals)

provided deeper insight into fluctuations within mastery goals as well. This is why we retained the six-profile solution, which provided an entropy of .64.

For the German-university study set, the fit differences pointed to a six-profile solution, as did the likelihood ratio tests. We did not observe a good class discrimination for more goal profiles, so we retained the six-profile solution, which provided an entropy of .76.

For the German-school study set, the fit differences were small after a six-profile model, while the likelihood ratio suggested a two-profile model that primarily reflected level differences in performance goals. In terms of content, the six-profile solution was the most meaningful; further profile solutions did not provide a good class discrimination. Despite only few teachers being classified into some of the profiles beyond a three-profile solution, we again retained the six-profile solution, which provided an entropy of .81 .

Finally, for the overall dataset, both the decrease in fit indices and the likelihood ratio tests clearly spoke for the six-profile solution. This was further supported by low class discrimination in seven or more profile solutions and meaningful mean levels for the six-profile solution. Therefore, we also retained the six-profile solution, which provided an entropy of .69.

\subsection{Configuration of Profiles}

Figure 1 shows the means of the achievement goals for the six-profile solutions for the different study sets and their combination. The profiles were similar for the different study sets, particularly between the Israeli- 


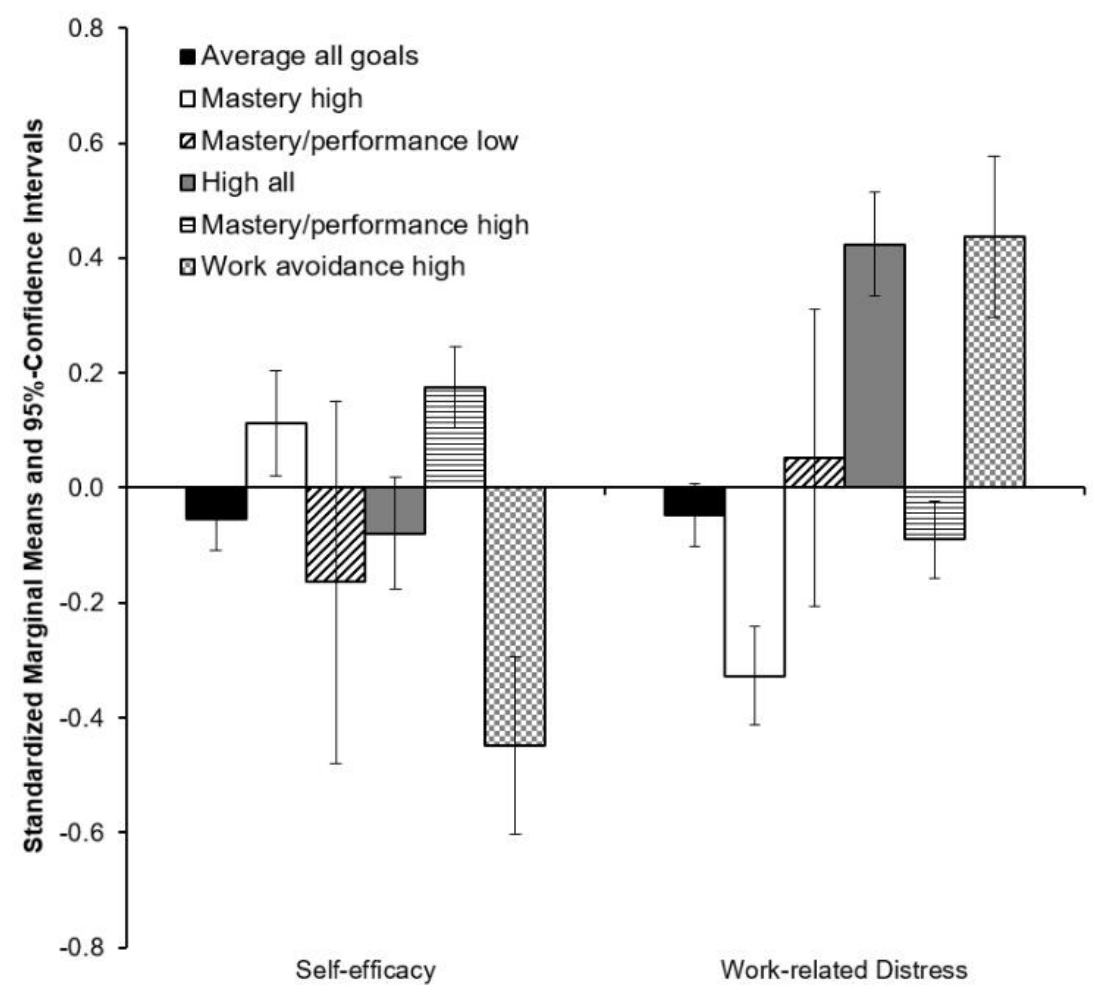

Figure 2. $z$-standardized marginal means and $95 \%$ confidence intervals for self-efficacy and

work-related distress levels in the six profiles

school and the German-university study sets. We observed a group of teachers that pursued as strong mastery goals as most of the other teachers and average levels of the other three goals $(\diamond)$. Overall, most teachers were classified into this profile. In the second profile, the teachers exhibited similar levels of mastery goals, but low levels of the other three goals $(\bullet)$. This profile was also similar across all three study sets and contained a substantial number of teachers. Another profile that was very similar across all three study sets entailed weak mastery and weak performance goals and average levels of work avoidance goals $(\mathbf{x})$. This profile contained the fewest number of teachers.

The configurations of the remaining three profiles varied a bit more across the study sets: First, there were two profiles with strong performance approach and performance avoidance goals. In the German-university study set, these had similarly strong levels of mastery goals but differed in the level of work avoidance goals, while in the Israel-school study set they differed in the level of mastery goals while work avoidance goals were similar between both profiles. In the Germanschool study set however, these two profiles also dif- fered in the quantitative level of performance goals. Finally, the last profile was characterized by rather weak mastery goals and average to strong performance and work avoidance goals. This profile was more pronounced in the German-school study set than the other two.

On the overall dataset level, we found very similar profiles as in the three study sets, with average goal levels ( $\diamond$; average all goals; $39 \%$ of participants), strong mastery and weak performance and work avoidance goals $(\bullet$; mastery high; $15 \%)$, weak mastery, weak performance, and average work avoidance goals (x; mastery/performance low; 2\%), strong mastery, performance, and work avoidance goals ( $\mathbf{\Delta}$; high all; 13\%), strong mastery and performance, but weak work avoidance goals ( $\square$; mastery/performance high; 25\%), as well as average mastery and performance goals combined with strong work avoidance goals ( $\mathbf{\square}$; work avoidance high; 6\%). In particular, it is worth pointing out that there were profiles that were characterized to the same extent by mastery (and work avoidance) goals, but had either strong, average, or weak performance goals. Indeed, these quantitative differences in 
Table 4

Results of Structural Equation Models Analyzing the Relations Between Goals Profiles and Individual Goals with Self-effiacy and Work-related Distress

\begin{tabular}{|c|c|c|c|c|}
\hline & \multicolumn{2}{|c|}{ Model 1: Goal profiles } & \multicolumn{2}{|c|}{ Model 2: Individual goals } \\
\hline & Self-efficacy & $\begin{array}{l}\text { Work-related } \\
\text { Distress }\end{array}$ & Self-efficacy & $\begin{array}{l}\text { Work-related } \\
\text { Distress }\end{array}$ \\
\hline \multicolumn{5}{|l|}{ Goal profile membership } \\
\hline Average all goals $(\diamond)$ & $-{ }^{\mathrm{a}}$ & $-^{\mathrm{a}}$ & & \\
\hline Mastery high $(\bullet)$ & $.07(p=.001)$ & $-.11(p<.001)$ & & \\
\hline Mastery/performance low (x) & $-.02(p=.41)$ & $.01(p=.66)$ & & \\
\hline High all $(\boldsymbol{\Delta})$ & $-.01(p=.74)$ & $.17(p<.001)$ & & \\
\hline Mastery/performance high ( $\square)$ & $.11(p<.001)$ & $-.02(p=.25)$ & & \\
\hline Work avoidance high ( $\square$ ) & $-.10(p<.001)$ & $.12(p<.001)$ & & \\
\hline \multicolumn{5}{|l|}{ Individual achievement goals } \\
\hline Mastery (learning approach) & & & $.25(p<.001)$ & $-.14(p<.001)$ \\
\hline Performance approach & & & $.23(p<.001)$ & $-.01(p=.837)$ \\
\hline Performance avoidance & & & $-.20(p<.001)$ & $.07(p=.03)$ \\
\hline Work avoidance & & & $-.14(p<.001)$ & $.29(p<.001)$ \\
\hline$R^{2}$ with $95 \%$ confidence interval & $\begin{array}{c}.028 \\
{[.016 ; .040]}\end{array}$ & $\begin{array}{c}.059 \\
{[.041 ; .077]}\end{array}$ & $\begin{array}{c}.135 \\
{[.104 ; .166]}\end{array}$ & $\begin{array}{c}.129 \\
{[.102 ; .157]}\end{array}$ \\
\hline
\end{tabular}

Note. $N=3,681$ teachers. Presented are standardized regression weights. Individual achievement goals, self-efficacy, and work-related distress were estimated as latent variables based on item parcels, $\chi^{2} \leq 116.49, \mathrm{CFA} \geq .998, \mathrm{TLI} \geq .996, \mathrm{RMSEA} \leq .016, \mathrm{SRMR} \leq .007$.

${ }^{\mathrm{a}}$ The average all profile was used as a reference group.

performance goals characterized the three most prevalent profiles that around three fourths of the overall sample was classified into. Interestingly, we did not identify any profiles that were characterized by performance approach and performance avoidance goals being pursued to different strength. Besides that, it should be noted that the high all and mastery/performance high profiles primarily differed by the extent to which work avoidance goals were pursued.

To confirm the generalizability of these profiles and test for possible context effects, we investigated whether the membership of a teacher to a particular profile could be attributed to the study set to which this teacher belonged. A multivariate regression with WLSMV as an estimator showed that none of the profiles were statistically significantly predicted by the study set $\left(R^{2}<.01, p>.37 ;|\beta| \leq .07, p>.11\right)$. This means that we did not find evidence for profile membership being a function of the different study sets, which additionally speaks to the generalizability of the profiles across the studies (as also reflected in the relatively similar order of profile frequency in the three study sets). ${ }^{3}$

\subsection{Associations of Goal Profiles with Teachers' Self-efficacy Beliefs and Work-related Distress}

To determine the explanatory power of the profiles, we conducted equality tests of the means of self-efficacy and work-related distress across the latent profiles. The results indicated small differences in self-efficacy between teachers that were classified into different profiles $\left(\chi^{2}=68.8, p<.001\right)$. Specifically, teachers in the work avoidance high profile reported lower selfefficacy beliefs than teachers in the average and high all profiles $\left(\chi^{2}=12.1-15.3, p<.001\right)$ as well as the mastery high and mastery/performance high profiles $\left(\chi^{2}=36.5-53.0, p<.001\right)$ that in turn had stronger selfefficacy beliefs than the average and high all profile $\left(\chi^{2} \geq 10.5-22.7, p \leq .002\right)$. Figure 2 displays marginal means and their 95\%-confidence intervals. For workrelated distress, we found a medium goal profile membership effect $\left(\chi^{2}=171.6, p<.001\right)$. Teachers in the mastery high profile reported less work-related distress than teachers from the other profiles $\left(\chi^{2} \geq 5.7, p \leq .02\right)$, particularly regarding teachers classified into the work avoidance high $\left(\chi^{2}=66.0, p<.001\right)$ and the high all profile $\left(\chi^{2}=126.8, p<.001\right)$ that both in turn reported 
more work-related distress than teaches from the mastery/performance low profile $\left(\chi^{2}=5.3-6.2, p \leq .02\right)$ as well as the average all goals and mastery/performance high profiles $\left(\chi^{2}=27.5-63.0, p<.001\right)$.

These differences in self-efficacy beliefs and workrelated distress were also evident in a structural equation model (see Table 4) where profile membership explained $3 \%$ of the variance in self-efficacy and $6 \%$ of the variance in work-related distress. Conversely, taking a variable-centered approach by investigating the effect of the individual goals instead of the goal profiles, we found that the individual achievement goals explained $14 \%$ of the variance in self-efficacy and $13 \%$ of the variance in work-related distress. Self-efficacy was positively related to mastery approach and performance approach goals and negatively related to performance avoidance and work avoidance goals, while work-related distress was negatively related to mastery goals, and positively to performance avoidance and work avoidance goals. Comparisons of the confidence intervals showed that the additive main effects of the achievement goals explained substantially more variance in the outcome variables than the goal profiles.

\section{Discussion}

We analyzed achievement goal profiles of teachers and their meaningfulness by investigating whether psychologically reasonable, coherent, and generalizable goal profiles can be found in different teacher populations, how such profiles are associated with teachers' self-efficacy and work-related distress, and how powerful such an approach can be compared to a more commonly used variable-centered approach. Strengths of the work include the consideration of multiple large datasets with similar measures from different educational settings, the investigation of goal profiles in a hitherto uninvestigated population, and the explicit comparison of exploratory power between profiles and individual goals.

Using large teacher samples from Israel and Germany as well as schools and universities and data about their mastery, performance approach, performance avoidance, and work avoidance goals, we found psychologically sensible and largely generalizable goal profiles that can be helpful in describing teachers' achievement goal pursuit. However, most profiles primarily differed by strength of performance goals and had only little explanatory value compared to the individual achievement goals. As such, a more critical picture results from the present study towards using achievement goal profiles in teachers.

\subsection{Is it Possible to Identify Meaningful Achieve- ment Goal Profiles in Teachers?}

Regarding our first question, we identified six achievement goal profiles in each of the different study sets. In order to overcome limitations of person-centered approaches, we also investigated the generalizability of the profiles across countries and educational settings. In doing so, we found profiles to be largely comparable across the study sets and not attributable to the study set used for the analyses. While the detected profiles were quite similar across the first two study sets (Israel school teachers, German university teachers), it needs to be considered that the less clear pattern emerged for the smallest study set (i.e., German school teachers; for which we observed only few teachers being classified into some of the profiles, and the high all and work avoidance high profile to be slightly more different in goal means to the respective profiles within the other two study sets). To this end, in the literature, there is currently no consensus regarding the minimum required sample sizes for LPAs (for an overview see Park \& Yu, 2018). In particular, prior research has indicated that the required sample sizes could vary depending on many aspects such as the number of indicators, the structure of the latent profiles, and covariates (Henson, et al., 2007; Nylund et al., 2007; Park \& Yu, 2018; Wurpts \& Geiser, 2014). Furthermore, it might also be possible to detect the correct number of profiles with small samples (Tein, Coxe, \& Cham, 2013), however, not yield clear patterns for some of the profiles. This indicates that requirements of LPAs may not always be fulfilled and that one needs to be cautious when running and interpreting such analyses.

The goal profiles that we consistently found were coined by quantitative as well as qualitative differences. Similar to the meta-analysis of students' achievement goal profiles by Wormington and Linnenbrink-Garcia (2017) and the LPA of vocational training instructors by Kunst et al. (2018), we found that the majority of participants were classified into an average all goals profile (39 percent overall) or a high all goals profile (13 percent overall). Further, our analyses documented that the studied participants mainly differed in mean levels of their performance goals but not so much in qualitatively different compositions of the other goals. In particular, the group with strong mastery and strong performance goals and the group with similarly strong mastery goals but much less strongly pursued performance goals were very similar to the respective profiles reported in Wormington and Linnenbrink-Garcia (2017), and line up with initial theorizing into the nature of achievement goal pursuit from a multiple goal perspective (pursuit of mastery and performance goals; e.g., Pintrich, 2000). Finding such profiles in different 
populations strongly speaks to their existence and to their sensibility in describing differences in achievement goal pursuit.

However, comparing our findings to these previous works, it also needs to be noted that the profiles that we found mostly did not strongly differ regarding mastery goals. In fact, nearly all participants were in a profile with similarly strong mastery goals, with no profile with stronger mastery goals standing out having been identified. This finding may be well in line with the generally strong mastery goals reported for the teacher population and could indicate differences in the goal pursuit between student and teacher populations (with teachers strongly valuing learning already; see also Butler, 2012; Daumiller et al., 2019b). Furthermore, while Wormington and Linnenbrink-Garcia (2017) conflated performance avoidance and work avoidance goals, we investigated them separately from each other. This proved to be very helpful in the present work, as we found substantial differences in goal profiles based on teachers' work avoidance goals (particularly regarding the high all vs. the mastery/performance high profiles). From a psychological perspective, it makes sense that teachers can pursue strong mastery and performance and either strong and little work avoidance goals. Our findings also point to the distinctiveness of work avoidance goals from other goals (particularly performance avoidance goals; see King \& McInerney, 2014) as well as the merits of including these goals for describing the pursuit of the different self-related aims that teachers may hold in achievement situations at work. Finally, as in Wormington and Linnenbrink-Garcia (2017), we did not find goal profiles that differed between performance approach and performance avoidance goals, which is in line with the strong correlation typically reported for this type of goal, particularly in research on teachers (see Daumiller et al., 2019; Janke et al., 2016). While it stands to reason that different groups of people should be able to be identified that differ in the extent to which they pursue performance approach and avoidance goals, these differences are likely much smaller than the differences regarding mastery and work avoidance goals, which is why they may not be readily found in latent profile analyses when also including these goals. Taken together, this suggests that combining performance approach and performance avoidance goals in profile analyses might not be particularly useful - at least when other achievement goals (such as mastery or work avoidance goals) are also considered.

In sum, goal profiles can theoretically be considered as sensible to describe how individuals actually pursue goals (multiple goals at the same time and to different strengths), however, the large proportion of profile differences due to mean level differences in performance goals might question the usefulness of the LPA approach (opposed to merely describing the strength to which they pursued the different achievement goals) for describing differences between different groups of people in the quality of their motivations.

\subsection{How Useful are Teachers' Achievement Goal Profiles in Explaining Differences in Teachers' Self- efficacy Beliefs and Work-related Distress Com- pared to Individual Goals?}

Regarding our second and third research questions, we did find differences in self-efficacy beliefs and work-related distress in teachers based on the goal profiles they were assigned to. However, these differences were primarily found for those profiles such as mastery high or work avoidance high in which one type of goal was substantially stronger than the others. Moreover, results for these profiles were in line with the positive associations typically reported under a variable-centered view for mastery goals, as well as with the negative associations for work-avoidance goals, with favorable levels of self-efficacy beliefs and work-related distress. Most importantly, we found that these inter-individual differences between teachers in their self-efficacy and work-related distress could be primarily traced back to individual goals and their additive effects. Compared to these effects, the goal profiles yielded hardly any explanatory value for teachers' selfefficacy and work-related distress. To the best of our knowledge, such direct comparisons between personcentered and variable-centered analyses have not yet been conducted (cf. Marsh et al., 2007; LinnenbrinkGarcia et al., 2012). It should be noted that the amount of explained variance may not be a fair comparison criterion for the two methods, as goal profile membership contains restricted variance compared to the strength to which the individual goals are pursued. Nevertheless, as researchers typically use these approaches with the ultimate aim of explaining differences in outcome variables, the amount of explained variance is a highly relevant criterion with regard to application purposes. Furthermore, the small amounts of explained variances raises concerns about using them as a basis for profilespecific interventions. Taken together, our findings on the comparison of these two approaches imply that asking "which profile is more beneficial" may not be a very beneficial question - especially when this question is asked with a pure exploratory focus and the analysis is not guided by justified hypotheses on the effects 
of these profiles (as is frequently the case in general applications of person-centered approaches). Instead, the individual achievement goals seem to be more useful in explaining differences in teachers' experiences and behaviors.

Regarding the multiple-goal perspective, this means that while this approach is likely adequate for describing actual goal pursuit, the core premise that functionality and effects of achievement goals would change substantially depending on their composition (see Pintrich, 2000; Senko, et al., 2011) cannot be confirmed with the present work. Instead, the main effects that we found are rather in favor of a mastery-goal perspective-similar to the most favorable effects having been reported for the high-mastery goal profiles by Wormington and Linnenbrink-Garcia (2017). While we only investigated self-efficacy beliefs and work-related distress in the teacher population, this finding may also hold true for other variables and populations, and thus warrants a more skeptical view on the merits of achievement goal profiles in explaining experiences and behaviors of individuals compared to the main effects of the individual goals.

\subsection{Limitations and Future Research}

Interpreting these findings, there are limitations of the current work that need to be borne in mind. First, while we used data from different studies and different institutions, not all of the measures were identical (albeit very similar). As such, it is likely that with the measures tapping on slightly different aspects, we could not have found perfectly identical profiles across the different study sets in the first place. This means that our findings on the generalizability of the different goal profiles across the different study sets can be expected to underestimate the actual similarities.

Second, we only investigated teachers from Israel and Germany. While the inclusion of different countries and types of institutions is a great strength of the present investigation, future research could profit from including even more different (e.g., Eastern) countries or other Western countries that place greater emphasis on teacher evaluation through high-stakes testing (e.g., the US). This could offer a very interesting perspective regarding the generalizability of different goal profiles.

Third, our findings are limited in that we only included learning, performance approach, performance avoidance, and work avoidance goals. While this lines up well with the majority of past research on teachers' goals, roots in the fundamental work by Butler (2007), and allows sensible comparisons to investigations into goal profiles in students, it should be noted that the profiles found might strongly depend on the different goals used (as indicated by our results for work avoidance goals). Future research might therefore also consider other goals, such as relational goals that have proven powerful in describing the motivations for teaching (Butler, 2014) and have also been used successfully in first investigations into academic and social goal profiles in students (Shim \& Finch, 2014).

Fourth, we used LPAs as a person-centered approach to studying teacher motivation. It should be considered that the background of person-centered analyses is to focus on the individual rather than on the population (thus the term "person-centered"; e.g. Bergman \& Trost, 2006; Wormington \& Linnenbrink-Garcia, 2017). However, in most studies, the "person-centered" approach is applied to compare subgroups of individuals on outcome variables (this is particularly true for research on goal profiles; e.g., Jang \& Liu, 2012; Pastor et al., 2007). In this case, the term "person-centered approach" is strictly speaking misleading and it might be more appropriate to speak of "pattern-centered or categorical latent variable" analyses that allow for the identification and comparison of subgroups within a given population. In contrast, it may be argued that personcentered analyses in a strict sense require variance within individuals and as such, multiple measurement occasions (Voelkle, Brose, Schmiedek, \& Lindenberger, 2014) to investigate the interplay of variables within persons or their shift between identified subgroups. Even though this terminology might therefore be considered as somewhat inaccurate, we used the term "person-centered approach" in the present work given that it is commonly used in the achievement goal literature when referring to analyses into goal profiles.

\subsection{Conclusions}

Taken together, our findings indicate that results from latent profile analyses may be fuzzier than often thought. Our findings imply that goal profiles make sense and can be a good approach to describing teachers' actual goal pursuit, with psychologically meaningful profiles that we consistently found across different study sets (albeit heavily relying on differences in the strength of performance goals instead of further qualitative differences in motivations). Nevertheless, finding goal profiles may not always be easy and depend on relevant methodological features such as the sample size. Moreover, the usefulness of this approach for explaining differences in teachers' cognitions and behaviors may be limited as goal profiles had little explanatory value compared to individual goals. As such, we consider goal profile analyses valuable for describing goal pursuit, but we also see danger in the unreflected use of such analyses and are skeptical about their added 
value for research on the correlates of teachers' achievement motivation and achievement goal research in general.

\section{References}

Ames, C., \& Archer, J. (1988). Achievement goals in the classroom. Journal of Educational Psychology, 80, 260267. https://doi.org/10.1037/0022-0663.80.3.260

Asparouhov, T., \& Muthén, B. O. (2013). Auxiliary variables in mixture modeling: A 3-step approach using Mplus (Mplus Web Notes: No. 15, Version 6). Retrieved from https://www.statmodel.com/examples/webnotes/webnote15.pdf

Asparouhov, T., \& Muthén, B. (2014). Auxiliary variables in mixture modeling: Using the BCH method in Mplus to estimate a distal outcome model and an arbitrary secondary model (Mplus Web Notes: No. 21, Version 7). Retrieved from https://www.statmodel.com/examples/webnotes/webnote21.pdf

Bauer, D. J., \& Curran, P. J. (2004). The integration of continuous and discrete latent variable models. Psychological Methods, 9, 3-29. https://doi.org/10.1037/1082989X.9.1.3

Bergman, L. R., \& Trost, K. (2006). The person-oriented versus the variable-oriented approach. Merrill-Palmer Quarterly, 52(3), 601-632.

Büssing, A., \& Glaser, J. (1998). Managerial stress und burnout. A collaborative international study (CISMS). Die deutsche Untersuchung (Forschungsbericht des Lehrstuhls für Psychologie Nr. 44). München, Germany: Technical University. Retrieved from http://www.psy.wi.tum.de/LS-Berichte/Bericht-44.pdf

Butler, R. (2007). Teachers' achievement goal orientations and associations with teachers' help seeking. Journal of Educational Psychology, 99, 241-252. https://doi.org/10.1037/0022-0663.99.2.241

Butler, R. (2012). Striving to connect. Journal of Educational Psychology, 104, 726-742. https://doi.org/10.1037/a0028613

Butler, R. (2014). What teachers want to achieve and why it matters: An achievement goal approach to teacher motivation. In P. W. Richardson, S. A. Karabenick, \& H. M. G. Watt (Eds.) Teacher motivation (pp. 42-57). Routledge.

Butler, R., \& Shibaz, L. (2008). Achievement goals for teaching as predictors of students' perceptions of instructional practices and students' help seeking and cheating. Learning and Instruction, 18, 453-467. https://doi.org/10.1016/j.learninstruc.2008.06.004

Butler, R., Shibaz, L., \& Levontin, L. (2020). Contextual and motivational antecedents of teachers' social support for students. AERA, San Francisco, 2020.

Cattell, R. B. (1966). The scree test for the number of factors. Multivariate Behavioral Research, 1, 245-276. https://doi.org/10.1207/s15327906mbr0102_10
Cho, Y., \& Shim, S. S. (2013). Predicting teachers' achievement goals for teaching. Teaching and Teacher Education, $32, \quad 12-21$. https://doi.org/10.1016/j.tate.2012.12.003

Collie, R. J., \& Martin, A. J. (2017). Teacher' sense of adaptability. Learning and Individual Differences, 55, 29-39. https://doi.org/10.1016/j.lindif.2017.03.003

Daumiller, M., Dickhäuser, O., \& Dresel, M. (2019). University instructors' achievement goals for teaching. Journal of Educational Psychology, 111, 131-148. https://doi.org/10.1037/edu0000271

Daumiller, M., \& Dresel, M. (2020). Teaching and research: Specificity and congruence of university faculty achievement goals. International Journal of Educational Research, 99. Advanced online publication. https://dx.doi.org/10.1016/j.ijer.2019.08.002

Daumiller, M., Grassinger, R., Dickhäuser, O., \& Dresel, M. (2016). Structure and relationships of university instructors' achievement goals. Frontiers in Psychology, 7. https://doi.org/10.3389/fpsyg.2016.00375

Daumiller, M., Rinas, R., Olden, D., \& Dresel, M. (2020). Academics' motivations in professional training courses. International Journal of Academic Development. Advanced online publication. https://doi.org/10.1080/1360144X.2020.1768396

Duda, J. L., \& Nicholls, J. G. (1992). Dimensions of achievement motivation in schoolwork and sport. Journal of Educational Psychology, 84(3), 290-299.

Elliot, A. J. (2005). A conceptual history of the achievement goal construct. In A. J. Elliot, \& C. S. Dweck (Eds.), Handbook of competence and motivation (pp. 52-72). New York, NY: Guilford.

Elliot, A. J., \& McGregor, H. A. (2001). A $2 \times 2$ achievement goal framework. Journal of Personality and Social Psychology, 80, 501-519. https://doi.org/10.1037/00223514.80.3.501

Elliot, A., Murayama, K., \& Pekrun, R. (2011). A 3 x 2 achievement goal model. Journal of Educational Psychology, 103, 632-648. https://doi.org/10.1037/a0023952

Enzmann, D., \& Kleiber, D. (1989). Helfer-Leiden [Helperdistress]. Heidelberg, Germany: Asanger.

Fasching, M. S., Dresel, M., Dickhäuser, O., \& Nitsche, S. (2010). Goal orientations of teacher trainees. Journal for Educational Research Online, 2(2), 9-33.

Friedman, I. A., \& Farber, B. A. (1992). Professional selfconcept as a predictor of teacher burnout. The Journal of Educational Research, 86, 28-35. https://doi.org/10.1080/00220671.1992.9941824

Gorozidis, G. \& Papaioannou, A. (2011). Teachers' self-efficacy, achievement goals, attitudes and intentions to implement the new Greek physical education curriculum. European Physical Education Review, 17, 231-253. https://doi.org/10.1177/1356336X11413654

Hakanen, J. J., Bakker, A. B., \& Schaufeli, W. B. (2006). Burnout and work engagement among teachers. Journal of School Psychology, 43, 495-513. https://doi.org/10.1016/j.jsp.2005.11.001 
Harackiewicz, J. M., Barron, K. E., Pintrich, P. R., Elliot, A. J., \& Thrash, T. M. (2002). Revision of achievement goal theory. Journal of Educational Psychology, 94, 638-645. https://doi.org/10.1037//0022-0663.94.3.638

Henson, J. M., Reise, S. P., \& Kim, K. H. (2007). Detecting mixtures from structural model differences using latent variable mixture modeling. Structural Equation Modeling: A Multidisciplinary Journal, 14, 202-226. https://doi.org/10.1080/10705510709336744

Hipp, J. R., \& Bauer, D. J. (2006). Local solutions in the estimation of growth mixture models. Psychological Methods, 11, 36-53. https://doi.org/10.1037/1082989X.11.1.36

Hulleman, C. S., Schrager, S. M., Bodmann, S. M., \& Harackiewicz, J. M. (2010). A meta-analytic review of achievement goal measures. Psychological Bulletin, 136, 422-449. https://doi.org/10.1037/a0018947

Jang, L. Y., \& Liu, W. C. (2012). $2 \times 2$ Achievement goals and achievement emotions. European Journal of Psychology of Education, 27, 59-76. https://doi.org/10.1007/s10212-011-0066-5

Janke, S., Bardach, L., Oczlon, S., \& Lüftenegger, M. (2019). Enhancing feasibility when measuring teachers' motivation. Teaching and Teacher Education, 83, 1-11. https://doi.org/10.1016/j.tate.2019.04.003

Janke, S., \& Dickhäuser, O. (2018). A situated process model of vocational achievement goal striving within members of the academic staff at university. Motivation and Emotion, 42, 466-481. https://doi.org/10.1007/s11031-0179657-z

Janke, S., Nitsche, S. und Dickhäuser, O. (2015). The role of perceived need satisfaction at work for teachers' workrelated learning goal orientation. Teaching and Teacher Education, $\quad 47, \quad 184-194$. https://doi.org/10.1016/j.tate.2015.01.009

Janke, S., Nitsche, S., Praetorius, A. K., Benning, K., Fasching, M., Dresel, M., \& Dickhäuser, O. (2016). Deconstructing performance goal orientations. Learning and Individual Differences, 50, 133-146. https://doi.org/10.1016/j.lindif.2016.08.013

Janssen, O., \& Van Yperen, N. W. (2004). Employees' goal orientations, the quality of leader-member exchange, and the outcomes of job performance and job satisfaction. Academy of Management Journal, 47, 368-384. https://doi.org/10.5465/20159587

Kaplan, A., \& Middleton, M. (2002). Should childhood be a journey or a race? Response to Harackiewicz et al. (2002). Journal of Educational Psychology, 94, 646-648. https://doi.org/10.1037/0022-0663.94.3.646

King, R. B., \& McInerney, D. M. (2014). The work avoidance goal construct. Contemporary Educational Psychology, 39, 42-58. https://doi.org/10.1016/j.cedpsych.2013.12.002

Klassen, R. M., \& Chiu, M. M. (2010). Effects on teachers' self-efficacy and job satisfaction. Journal of Educational Psychology, 102,
https://doi.org/10.1037/a0019237
Kunst, E. M., van Woerkom, M., \& Poell, R. F. (2018). Teachers' goal orientation profiles and participation in professional development activities. Vocations and Learning, 11, 91-111. https://doi.org/10.1007/s12186017-9182-y

Linnenbrink-Garcia, L., Pugh, K. J., Koskey, K. L., \& Stewart, V. C. (2012). Developing conceptual understanding of natural selection. The Journal of Experimental Education, $\quad 80, \quad 45-68$. https://doi.org/10.1080/00220973.2011.559491

Litalien, D., Morin, A. J., \& McInerney, D. M. (2017). Generalizability of achievement goal profiles across five cultural groups. Contemporary Educational Psychology, 51, 267-283.

https://doi.org/10.1016/j.cedpsych.2017.08.008

Little, T. D., Cunningham, W. A., \& Shahar, G. (2002). To parcel or not to parcel. Structural Equation Modeling, 9, 151-173. https://doi.org/10.1207/s15328007sem0902_1

Marsh, H. W., Lüdtke, O., Trautwein, U., \& Morin, A. J. (2009). Classical latent profile analysis of academic selfconcept dimensions. Structural Equation Modeling, 16, 191-225. https://doi.org/10.1080/10705510902751010

Mascret, N., Elliot, A. J., \& Cury, F. (2017). The $3 \times 2$ achievement goal questionnaire for teachers. Educational Psychology, 37, 346-361. https://doi.org/10.1080/01443410.2015.1096324

Maslach, C., Jackson, S. E., \& Leiter, M. P. (1986). Maslach burnout inventory. Paolo Alto, CA: CPP.

Midgley, C., Kaplan, A., \& Middleton, M. (2001). Performance-approach goals. Journal of Educational Psychology, 93, 77-86. https://doi.org/10.1037/00220663.93.1.77

Morin, A. J. (2016). Person-centered research strategies in commitment research. In J. Meyer (Ed.), Handbook of employee commitment (pp. 490-508). Cheltenham, England: Edward Elgar.

Morin, A. J., Morizot, J., Boudrias, J. S., \& Madore, I. (2011). A multifoci person-centered perspective on workplace affective commitment. Organizational Research Methods, 14, 58-90. https://doi.org/10.1177/1094428109356476

Muthén, L., \& Muthén, B. (2017). Mplus (version 8.1) [Computer Software]. Los Angeles, CA: Muthén \& Muthén.

Nitsche, S., Dickhäuser, O., Fasching, M. S., \& Dresel, M. (2011). Rethinking teachers' goal orientations. Learning and Instruction, 21, 574-586. https://doi.org/10.1016/j.learninstruc.2010.12.001

Nitsche, S., Dickhäuser, O., Fasching, M. S., \& Dresel, M. (2013). Teachers' professional goal orientations. Learning and Individual Differences, 23, 272-278. https://doi.org/10.1016/j.lindif.2012.07.017

Nylund, K. L., Asparouhov, T., \& Muthén, B. O. (2007). Deciding on the number of classes in latent class analysis and growth mixture modeling. Structural Equation Modeling, $\quad 14, \quad$ 535-569. https://doi.org/10.1080/10705510701575396 
Park, J., \& Yu, H. T. (2018). Recommendations on the sample sizes for multilevel latent class models. Educational and Psychological Measurement, 78, 737-761. https://doi.org/10.1177/0013164417719111

Parker, P. D., \& Martin, A. J. (2009). Coping and buoyancy in the workplace. Teaching and Teacher Education, 25, 68-75. https://doi.org/10.1016/j.tate.2008.06.009

Parker, P. D., Martin, A. J., Colmar, S., \& Liem, G. A. (2012). Teachers' workplace well-being. Teaching and Teacher Education, 28, 503-513. https://doi.org/10.1016/j.tate.2012.01.001

Pastor, D. A., Barron, K. E., Miller, B. J., \& Davis, S. L. (2007). A latent profile analysis of college students' achievement goal orientation. Contemporary Educational Psychology, 32, 8-47. https://doi.org/10.1016/j.cedpsych.2006.10.003

Peugh, J. L., \& Enders, C. K. (2004). Missing data in educational research. Review of Educational Research, 74, 525-556. https://doi.org/10.3102/00346543074004525

Pintrich, P. R. (2000). Multiple goals, multiple pathways. Journal of Educational Psychology, 92, 544-555. https://doi.org/10.1037/0022-0663.92.3.544

Retelsdorf, J., Butler, R., Streblow, L., \& Schiefele, U. (2010). Teachers' goal orientations for teaching. Learning and Instruction, 20, 30-46. https://doi.org/10.1016/j.learninstruc.2009.01.001

Retelsdorf, J., \& Günther, C. (2011). Achievement goals for teaching and teachers' reference norms. Teaching and Teacher Education, 27, 1111-1119. https://doi.org/10.1016/j.tate.2011.05.007

Schöne, C., Dickhäuser, O., Spinath, B., \& Stiensmeier-Pelster, J. (2012). SESSKO Skalen zur Erfassung des schulischen Selbstkonzepts [Scales for the assessment of academic self-concept] (2nd ed.). Göttingen, Germany: Hogrefe.

Schwarzer, R., \& Hallum, S. (2008). Perceived teacher selfefficacy as a predictor of job stress and burnout. Applied Psychology, 57, 152-171. https://doi.org/10.1111/j.1464-0597.2008.00359.x

Senko, C., Hulleman, C. S., \& Harackiewicz, J. M. (2011). Achievement goal theory at the crossroads. Educational Psychologist, 46, 26-47. https://doi.org/10.1080/00461520.2011.538646

Shieh, G. (2009). Detecting interaction effects in moderated multiple regression with continuous variables power and sample size considerations. Organizational Research Methods, 12, 510-528. https://doi.org/10.1177/1094428108320370

Shim, S. S., \& Finch, W. H. (2014). Academic and social achievement goals and early adolescents' adjustment: A latent class approach. Learning and Individual Differences, 30, 98-105. https://doi.org/10.1016/j.lindif.2013.10.015

Tein, J. Y., Coxe, S., \& Cham, H. (2013). Statistical power to detect the correct number of classes in latent profile analysis. Structural Equation Modeling, 20, 640-657. https://doi.org/10.1080/10705511.2013.824781

Tschannen-Moran, M., \& Hoy, A. W. (2001). Teacher efficacy. Teaching and Teacher Education, 17, 783-805. https://doi.org/10.1016/S0742-051X(01)00036-1

Tuominen-Soini, H., Salmela-Aro, K., \& Niemivirta, M. (2011). Stability and change in achievement goal orientations. Contemporary Educational Psychology, 36, 82100. https://doi.org/10.1016/j.cedpsych.2010.08.002

Wang, H., Hall, N. C., Goetz, T., \& Frenzel, A. C. (2017). Teachers' goal orientations. British Journal of Educational Psychology, 87, 90-107. https://doi.org/10.1111/bjep.12137

Van den Berghe, L., Soenens, B., Aelterman, N., Cardon, G., Tallir, I. B., \& Haerens, L. (2014). Within-person profiles of teachers' motivation to teach. Psychology of Sport and Exercise, 15, 407-417. https://doi.org/10.1016/j.psychsport.2014.04.001

Vansteenkiste, M., Sierens, E., Soenens, B., Luyckx, K., \& Lens, W. (2009). Motivational profiles from a self-determination perspective. Journal of Educational Psychology, 101, 671-688. https://doi.org/0.1037/a0015083

Veermans, M., \& Tapola, A. (2004). Primary school students' motivational profiles in longitudinal settings. Scandinavian Journal of Educational Research, 48, 373 395. https://doi.org/10.1080/0031383042000245780

Voelkle, M. C., Brose, A., Schmiedek, F., \& Lindenberger, U. (2014). Toward a unified framework for the study of between-person and within-person structures. Multivariate Behavioral Research, 49, 193-213. https://doi.org/10.1080/00273171.2014.889593

Wang, J., Shen, B., Luo, X., Hu, Q., \& Garn, A. C. (2018). Validation of a teachers' achievement goal instrument for teaching physical education. Journal of Teaching in Physical Education, 37, 91-100. https://doi.org/10.1123/jtpe.2016-0210

Wormington, S. V., \& Linnenbrink-Garcia, L. (2017). A new look at multiple goal pursuit. Educational Psychology Review, 29, 407-445. https://doi.org/10.1007/s10648016-9358-2

Wurpts, I. C., \& Geiser, C. (2014). Is adding more indicators to a latent class analysis beneficial or detrimental. Frontiers in Psychology, 5, 920-931. https://doi.org/10.3389/fpsyg.2014.00920

Note. This is a pre-copyedited, author-produced PDF of an article submitted for publication. This paper is not the copy of record and may not exactly replicate the final, authoritative version of the article. The final article will be available, upon publication, via its DOI. 


\section{Footnotes}

${ }^{1}$ In the present study, we focus on learning (approach) goals (defined by intraindividual competence gains) as a central component of the superordinate mastery goal construct (that also comprises task standards and avoidance valence, see Elliot, Murayama, and Pekrun, 2011).

${ }^{2}$ We also report the Akaike information criterion (AIC) for informational purposes but do not use it for model evaluation as it has a tendency for overextraction (see e.g., Henson, Reise, \& Kim, 2007; Nylund, Asparouhov, \& Muthén, 2007).

${ }^{3} \mathrm{We}$ also investigated whether the goal profiles would reflect gender differences or differences in teaching experience. Bivariate correlations indicated two statistically significant but very weak associations with gender where female teachers were slightly more frequently represented in the average profile than male teachers $(r=.06, p=.001)$, and slightly less frequently represented in the work-avoidant profile $(r=-.06, p=.001)$. No additional gender effects reached statistical significance $(|r| \leq .03, p>.07)$ and there were no statistically significant associations between goal profiles and teaching experience $(|r| \leq .03, p>.15)$. Taken together, these little differences may speak to the general nature of these profiles and line up with the little differences in goal pursuit typically found for demographic statistics (see in particular Hulleman et al., 2010). 